\title{
Effects of titles on the processing of text and lexically ambiguous words: Evidence from eye movements
}

\author{
JENNIFER WILEY \\ Washington State University, Vancouver, Washington \\ and \\ KEITH RAYNER \\ University of Massachusetts, Amherst, Massachusetts
}

\begin{abstract}
Providing titles for passages improves the comprehension and memorability of text. Titles have generally been thought to facilitate comprehension at later stages of processing. Consistent with prior research, we found that passages presented with titles were better recalled than those without titles. Furthermore, in Experiment 1, the presence of titles led to fewer regressive eye movements, shorter end-of-sentence reading times, and shorter fixation times on target nouns. Experiments 2 and 3 , using ambiguous target words, indicated that except when a very infrequent sense of a word is required, titles provide a strong enough context to allow for ambiguous words to be processed as quickly as control words. The results of the three experiments suggest that titles affect processing at both integrative and lexical stages of reading.
\end{abstract}

When readers are provided with a title for a text, the text is generally read faster, rated as more comprehensible, and recalled better than when it is presented without a title (Bransford \& Johnson, 1972; Dooling \& Lachman, 1971; Smith \& Swinney, 1992). This has been demonstrated most dramatically with passages that make very litthe sense without a title even though each individual sentence is grammatical and locally coherent. Consider, for example, this excerpt based on Bransford and Johnson's (1972) materials:

The procedure is actually quite simple. First you arrange things into different groups depending on their makeup. Of course, one pile may be sufficient depending on how much there is. If you have to go somewhere else due to lack of facilities that is the next step. It is important not to overdo it. It is better to do too few things at once than too many. (p. 722)

If readers know that this passage is about washing clothes, then they are able to instantiate several of the terms. The "procedure" is doing laundry, and the "things" are clothes.

This research was supported by Grant HD17246 from the National Institutes of Health and was conducted while the first author was supported by a postdoctoral fellowship on NIMH Training Grant MH16745 and the second author was supported by Research Scientist Award MH01255 from the National Institute of Mental Health. The authors thank Charles Clifton, Bob Lorch, Joe Magliano, and Matt Traxler for their helpful comments on earlier versions of the article. Correspondence should be addressed to J. Wiley, Department of Psychology, University of Illinois, Chicago, IL 60607 (e-mail: jwiley@uic.edu).
Furthermore, the schema allows for relations between terms to be made easily; thus, the clothes are put into "groups" that are the same as "piles." In effect, titles provide a context into which individual ideas, propositions, or sentences can be integrated. Thus, the presence of a title is thought to facilitate processing at a discourse or macrostructural level (Kintsch, 1988; Thorndyke, 1977) by providing clear relations between the propositions (Smith \& Swinney, 1992; St. George, Mannes, \& Hoffman, 1994). Support for this general explanation was provided by Smith and Swinney (1992), who created procedural passages similar to Bransford and Johnson's "Washing Clothes" passage to evaluate the relation between on-line processing and memory. Using a selfpaced sentence reading procedure, they found evidence for titles facilitating integrative stages of processing, because the reading of passages without titles was especially slow for sentences with low conceptual overlap. However, the self-paced sentence reading procedure precluded a more detailed analysis of how titles facilitated processing, leaving open the question of exactly how the presence of titles may benefit reading processes.

The focus of the present study was to determine specifically which reading processes the presence of titles affects by recording readers' eye movements. In particular, we were interested in three aspects of the reading process. First, we were interested in whether longer reading times when passages do not have titles are in fact due to integration difficulties. To investigate this issue, we examined both regressions (eye movements back to earlier read material) and end-of-sentence wrap-up effects. These measures are typically assumed to reflect the difficulty that the 
reader is having integrating aspects of the text (Just \& Carpenter, 1980; Rayner, 1998). Second, we were interested in whether the presence of titles affects the reading times of individual words. Third, if there indeed are effects of titles at the word level, we were interested in whether they are due in part to facilitation in lexical access. We investigated this issue by examining whether titles affect the processing of ambiguous words.

In relation to the first issue, longer reading times on untitled passages may be due to an increase in regressive fixations. Relative to forward fixations, which are generally assumed to be influenced by word identification processes $^{1}$ (Rayner, 1998; Reichle, Pollatsek, Fisher, \& Rayner, 1998), regressions seem to be more influenced by higher order factors, such as difficulties in comprehending the text (Rayner, 1998; Rayner \& Pollastek, 1989). And, as already noted, passages without titles are generally rated as less comprehensible than passages with titles.

Regressions due to comprehension difficulty have been most reliably observed with syntactically ambiguous sentences in which readers encounter a word that indicates that a previous analysis of the sentence was invalid (Frazier \& Rayner, 1982). In these cases in which readers must construct a new interpretation of the sentence, they not only fixate longer on the disambiguating word, but they are also much more likely to make a regression. Another case in which regressions are especially likely is when readers encounter an unexpected word (Ehrlich \& Rayner, 1983). Furthermore, a number of studies have demonstrated that regressions are used to aid in the integration of text segments and that difficulties in higher level processes, such as building a discourse model, result in more regressions (Blanchard \& Iran-Nejad, 1987; Hyönö, 1993; Shebilske \& Fisher, 1983; Vauras, Hyönö, \& Niemi, 1992). For example, Vauras et al. found that structurally incoherent passages led to more regressions than did coherent passages.

Longer overall reading times for untitled passages may also be due to longer fixation times at the ends of sentences. In general, fixations on words at the ends of sentences tend to be longer than fixations on words within the sentences. These "wrap-up" effects are generally assumed to reflect additional processing associated with understanding the sentence (Just \& Carpenter, 1980; Rayner, Kambe, \& Duffy, 2000; Rayner, Sereno, Morris, Schmauder, \& Clifton, 1989). Furthermore, the size of the wrap-up effect is influenced by the difficulty of understanding each sentence and, in particular, how hard it is to integrate each sentence with earlier text. For example, Just and Carpenter (1978) found that reading times increased when an inference had to be made in order to relate a new sentence to some previous portion of text. In their study, the sentence pair

It was dark and stormy the night the millionaire was murdered. The killer left no clues for the police to trace.

was read faster than the sentence pair

It was dark and stormy the night the millionaire died. The killer left no clues for the police to trace.
In reading the second pair of sentences, there was a strong tendency for readers to pause at the lexical item in question (in this case, "killer") and at the end of the sentence that contained it. On the other hand, when the connection between the concepts mentioned in adjacent sentences was more clear, less time was required at wrap-up and on the terms themselves. Thus, the results of these studies support the hypothesis that difficulties associated with higher order processes, such as comprehension and integration, should result in an increased number of regressions and inflated wrap-up times.

In relation to the present study, titles may facilitate the reading of text by providing clear relations between propositions, thereby aiding the higher order processes of integration and comprehension. If reading without a title complicates such higher order reading processes, then both an increase in regressions and an inflation in wrapup times would contribute to longer reading times when a passage is presented without a title. In addition, as mentioned above, there is some evidence that by making the relations between sentences less clear, the lack of titles may increase fixations on the referring words themselves. This suggests that titles may provide a context that could also affect the processing of individual words. Furthermore, there are a number of other eye-movement studies that show that providing a strong context can speed the processing of individual words. For example, Balota, Pollatsek, and Rayner (1985) found that a sentence context that increased the predictability of a target word decreased fixation times on that word (see also Rayner \& Well, 1996). Morris (1994) also demonstrated that words are processed faster when they are preceded by an appropriate sentence than when they are preceded by an inappropriate sentence, whether the context is instantiated by the underlying message of the sentence or by semantic associates. However, it should be noted that these effects of context on word identification have primarily been observed using context manipulations at the local/sentence level. There is some question as to whether or not manipulations in global context affect fixation times on individual words. For example, whereas Schustack, Ehrlich, and Rayner (1987) found effects of global context on fixation times on target words, Hyönö (1993) failed to find effects on word reading due to the introduction of an appropriate theme. Thus, it is an open question whether titles provide enough context, or the right kind of context, to facilitate word-level processing as measured by fixation times. Therefore, the second issue addressed by the present study was whether an effect of titles may be seen in fixation times on individual words.

The third issue is if such title effects in fixation times on individual words are obtained, whether they are due to discourse-level effects, such as ease of integration, or whether the title context may also facilitate lexical access or meaning selection. One way to approach this issue is to see whether titles affect the processing of ambiguous words. Ambiguous words have been used in a number of eye-movement studies (Binder \& Rayner, 1998; Dopkins, Morris, \& Rayner, 1992; Duffy, Morris, \& Rayner, 1988; 
Rayner \& Duffy, 1986; Rayner \& Frazier, 1989; Rayner, Pacht, \& Duffy, 1994; Sereno, Pacht, \& Rayner, 1992) to investigate the role of context in relation to lexical processing. The general findings from this research are as follows. First, when the context preceding the ambiguous target word is neutral, readers look longer at balanced ambiguous words (words with two equally likely interpretations) than at either (1) control words matched on length and frequency to the ambiguous word or (2) biased ambiguous words (words with a highly dominant interpretation). Second, when the context instantiates the appropriate meaning of the word, readers look no longer at a balanced word than at a frequency- matched/lengthmatched control word. Likewise, when the context instantiates the dominant meaning of a biased word, fixations are relatively short. However, if the context instantiates the subordinate meaning of a biased word, readers look longer at it than at a frequency-matched/length-matched control word. This latter result has been termed the $s u b$ ordinate bias effect. When readers take longer to read ambiguous words than control words, we assume that it is because multiple senses of the words are competing and that the required sense of the word for the context has not been selectively accessed. When ambiguous words can be read as fast as control words, it suggests that the required meaning has been selectively accessed.

In relation to the present study, the question is whether titles, like the context manipulations used in the above studies, provide a context that affects the processing of lexically ambiguous words. We were particularly interested the processing of subordinate meanings of biased words, since there is currently some controvers $y^{2}$ over the extent to which context can override the subordinate bias effect and allow for the selective access of the subordinate sense of a word (see Rayner, Binder, \& Duffy, 1999; Vu \& Kellas, 1999).

In the present experiments, we investigated the above issues by recording readers' eye movements as they read passages of text. In Experiment 1, we examined how titles facilitate processing by presenting vague texts with and without titles. We began by first replicating previous recall and global reading-time results. Then we moved to analyses of eye-movement data and examined regressions, reading times at the ends of sentences, and fixation times on individual nouns. In Experiments 2 and 3, we investigated the effects of titles on the reading of individual words and, in particular, whether titles influence lexical access, by using passages that contained ambiguous words. Two manipulations were used to investigate this issue. In Experiment 2, passages contained ambiguous words and were presented with or without titles. In Experiment 3, titled passages either contained ambiguous words or length- and frequency-matched control words. In both of these experiments, we were interested in whether titles led to the selective access of balanced or subordinate meanings of ambiguous words.

\section{EXPERIMENT 1 \\ Reading Vague Texts With and Without Titles}

The focus of Experiment 1 was to confirm the proposed effects of titles on integration and discourse-level processing and to investigate whether the effects of titles may be seen on word-level processing by recording readers' eye movements. In Experiment 1, the Bransford and Johnson (1972) and Dooling and Lachman (1971) passages were presented on a computer screen while readers' eye movements were monitored. Total passage reading time, time spent in regressions, number of regressions, time spent at the end of sentences, and fixation times on individual words were measured. If the facilitating effect of titles is related to advantages at an integrative stage of discourse representation, then fewer regressions and shorter wrap-up times are expected when readers are given titles. If speed-up is seen in fixation times on individual words, it suggests that titles may facilitate processing at a lexical level as well.

\section{Method}

Participants. Thirty-two students at the University of Massachusetts participated in this experiment. The participants received either class credit or $\$ 8$ as compensation. All participants were native English speakers. They either had normal uncorrected vision or wore soft contact lenses.

Materials. The four experimental passages were adapted from Bransford and Johnson (1972) and Dooling and Lachman (1971). Each participant saw two passages with titles and two without. In the no-title condition, the message "Get ready for the next passage" was presented in place of a title. The passages are included in Appendix A.

Apparatus. Eye movements were recorded by a Fourward Technologies Dual Purkinje Eyetracker, which has a resolution of $10^{\prime}$ of arc. Viewing was binocular, with eye position recorded from the right eye. The eyetracking system was interfaced with a 486 computer that ran the experiment. Passages were presented in doublespaced format on a VGA monitor. The letters were in lowercase except for the first letter of sentences and proper nouns. The participants were seated $62 \mathrm{~cm}$ from the monitor, with four letters subtending $1^{\circ}$ of visual angle. Brightness was adjusted to the comfort of the reader and held constant throughout the experiment. The passages were presented with no more than 60 letter spaces per line and were 8-10 lines long.

Procedure. When the participant arrived, a bite bar was prepared to minimize head movements, and the eyetracking system was calibrated. Calibration was generally completed in less than $5 \mathrm{~min}$. Each participant read a series of passages on a computer screen. The participants were told to read for comprehension and that, at the end of each passage, they would be asked a question about the passage they had just read to which they could respond with a simple yes-no response. It was stressed that they should read as normally as possible.

At the start of each trial, five boxes appeared at the top of the screen, and the participants were asked to look at the leftmost box. When the participants fixated on that box, a title or a "Get ready" message was presented. After reading the title or message, the participants pressed a button to erase it, and the five boxes reappeared. Once the participants again fixated on the leftmost box, the experimenter presented the passage. After reading the passage, the par- 
Table 1

Reading Times, Regressions, and Measures of Individual Words in Experiment 1

\begin{tabular}{lcc}
\hline & \multicolumn{2}{c}{ Condition } \\
\cline { 2 - 3 } & Title & No Title \\
\hline Recall (nouns) & 9.3 & 3.4 \\
Reading time per passage (sec) & 29.9 & 31.0 \\
Mean regression measures per passage & & \\
$\quad$ Time spent in regressions (msec) & 3,236 & 4,433 \\
$\quad$ Number of regressions made & 13 & 17 \\
Sentence wrap-up time & 306 & 354 \\
Individual noun measures (msec) & & \\
$\quad$ First fixation & 279 & 283 \\
$\quad$ Gaze duration & 330 & 362 \\
$\quad$ Total time & 376 & 421 \\
Empty phrase measures (msec) & & \\
$\quad$ First fixation & 271 & 272 \\
$\quad$ Gaze duration & 380 & 380 \\
$\quad$ Total time & 471 & 454 \\
\hline
\end{tabular}

ticipants pressed a button that erased the passage, and a question appeared on the screen.

The participants read two passages in a practice session, followed by the test session that contained four experimental passages and eight nonexperimental passages. Passages were presented in counterbalanced order, except that the "Washing Clothes" passage was always presented last. After each passage, the participants responded to a "yes" or "no" comprehension question. Immediately after the participants answered the last comprehension question, they were unexpectedly asked to write down all they could remember of the last passage that they had read. Recall was based on the number of nouns recalled in written protocols (using a verbatim criterion). An end-of-sentence measure was based on the gaze duration (the sum of all fixations on a word prior to moving to another word) on the last word in each of the 36 sentences. An individual word measure was based on gaze durations on 10 nouns in each passage. These words were selected from the possible set of nouns so that they (1) were not the last word in a sentence, and, if possible, (2) were not a repetition of a word used earlier in the passage, (3) were not a necessarily anaphoric noun such as thing, and, if possible, (4) were not in the first or last line of a passage as it appeared on the screen, and (5) were more than four letters long to maximize the probability of fixation. The 10 target nouns for each passage are presented in bold type in Appendix A. The target nouns had a mean length of 7.1 letters and a mean frequency of 96 (Francis \& Kučera norms, 1982).

\section{Results and Discussion}

With the exception of recall, which was analyzed between participants, each measure was analyzed by performing repeated measures analyses of variance (ANOVAs) on individual means based on subject variability. Because of the small number of passages, no items analyses were performed on the passage-level variables (overall reading times, regressions). Gaze durations on target words were analyzed in terms of both subject $\left(F_{1}\right)$ and item $\left(F_{2}\right)$ variability. Significance was $<.05$, unless otherwise noted.

Recall. Experiment 1 replicated the classic effect of titles on recall (see Table 1). The participants who read the "Washing Clothes" passage with a title recalled significantly more nouns than did the no-title group $[F(1,30)=$ $\left.15.02, M S_{\mathrm{e}}=18.4\right]$. Thus, consistent with previous studies
(Bransford \& Johnson, 1972; Dooling \& Lachman, 1971), titles were found to improve the recall of text.

Discourse-level measures. The second major question was whether titles could be demonstrated to affect discourse level variables and, in particular, variables related to integrative processing. The overall reading-time measure was also consistent with previous studies: The participants read passages with titles faster than they read those without $\left[F(1,31)=4.04, M S_{\mathrm{e}}=11,120\right]$. As shown in Table 1, the participants spent less time in regressions when passages were presented with titles than when passages were presented without titles $\left[F(1,31)=5.01, M S_{\mathrm{e}}=\right.$ $7,811]$ and made fewer regressive fixations $[F(1,31)=$ $4.20, M S_{\mathrm{e}}=113$ ].

With respect to wrap-up effects, as shown Table 1, the participants' gaze durations were longer on the last word in a sentence when passages were presented without titles than when they were presented with titles $\left[F_{1}(1,31)=\right.$ $\left.19.1, M S_{\mathrm{e}}=1,970 ; F_{2}(1,35)=20.8, M S_{\mathrm{e}}=2,139\right]$. Taken together, the regression and wrap-up results confirm that processing advantages were found at the discourse level for passages with titles and that longer overall reading times were due, at least in part, to difficulties in integrating text material without titles.

Word-level measures. The third major question in this experiment was whether effects of titles would be seen on the reading of individual words. The primary measure of reading time on target nouns that we examined was the gaze duration. For completeness, first fixation duration ${ }^{3}$ and total time are presented in Table 1. Since gaze duration is the most frequently cited measure associated with the processing time for a fixated word (Rayner, 1998), we will focus on the ANOVAs for that measure. If a target word was not fixated, the closest fixation within three letter spaces to the left and one letter to the right was counted as the fixation during which the target word was processed. This procedure is based on research that demonstrates that when readers do not fixate on a target word, they identify it on the prior fixation but that this takes place in a limited region (Rayner \& Pollatsek, 1989). Nine percent of the data were missing due to the participants' not fixating on the target word. An additional 3\% of the data were eliminated because fixations were shorter than $140 \mathrm{msec}$ or longer than $800 \mathrm{msec}$. When readers fixate on a word for such a short time, it is highly likely that much of the processing associated with the word was done on the previous fixation, whereas long fixation times are most likely due to track losses (Morrison, 1984).

The gaze durations for the participants who read passages with titles were significantly shorter on target nouns than were the gaze durations for the participants who did not receive titles $\left[F_{1}(1,31)=15.6, M S_{\mathrm{e}}=1,036 ; F_{2}(1,39)=\right.$ $\left.16.2, M S_{\mathrm{e}}=1,394\right]$. Although the main comparison of interest was between the reading of nouns in the title and no-title conditions, an additional control was included to ensure that the faster processing of words in the title condition was not due to titles simply speeding up reading rate overall. An empty-phrase measure was based on the 
reading times of five regions in each passage containing words such as can be very, seldom, and sometimes. The empty phrases used for this analysis are indicated by underlines in Appendix A. As shown in Table 1, no difference was found in any of the fixation-time measures for the empty phrases $(F \mathrm{~s}<1.15)$. This control suggests that faster reading in the title condition was not due to the participants' uniformly increasing their reading rate.

In summary, the results of Experiment 1 suggest that titles provide a context that speeds processing at multiple levels. At one level, the presence of a title can facilitate the integration of propositions. When textual information has been adequately incorporated into a mental representation, fewer regressions are necessary, and this speeds reading. Furthermore, when relations between sentences are clear, it eases the demands at sentence wrap-up, which also speeds reading. In addition, the results suggest facilitation may also be found in the reading of individual words, since nouns were read faster when passages were presented with titles. An important question is whether this speed-up is due to the same mechanism as the other effects - namely ease of integration or discourse representation-or whether the facilitation in the reading of individual words may also be due in part to facilitation in lexical access.

\section{EXPERIMENT 2 \\ Reading Texts With Ambiguous Words With and Without Titles}

The results of Experiment 1 suggest that titles facilitate the processing of individual words since they yielded shorter gaze durations on target nouns. In Experiments 2 and 3, we investigated whether titles effect lexical access by examining the effects of a title on the reading of ambiguous words. The passages used for Experiments 2 and 3 (based on Anderson, Reynolds, Schallert, \& Goetz, 1977, and Schallert, 1976) had two distinct interpretations, depending on which of two titles were given. For example, the following passage had two titles, "Worries of a Baseball Team Manager" and "Worries of a Ceramics Factory Manager":

In the last days of August, we were all suffering from the unbearable heat. Our daily job had turned from fun into hard labor. "All we need now is a strike," said the manager. The tone of his voice warned that he was about to leave the field. I could not help him. I hit a fly. "I guess things could get even worse," he sighed. "Our most valuable pitchers might crack in this heat. If only we had a lot more fans, we would all feel better. Or, if our best man came home I'd be happier. Oh well, a walk would cheer me up a little," the manager said as he turned away.

Importantly, these passages contained ambiguous words that allowed for the same passages to have alternate interpretations. In the above example, the words in bold have more than one meaning. The presence of the ambiguous words in these passages allows for a direct test of the influence of titles on lexical access-that is, whether the presence of a title affects gaze durations on ambiguous words. Since the title contexts instantiated dominant, subordinate, or balanced meanings of ambiguous words, if titles are effective contexts, the same pattern of results should emerge as when context is manipulated sententially. In previous research, the effect of context has been demonstrated in two ways: (1) observing fixation times when an ambiguous word is presented with or without a prior disambiguating context (Rayner \& Frazier, 1989) and (2) observing fixation times when ambiguous words and length- and frequency-matched control words are presented in the same sentence with a prior disambiguating context (Duffy et al., 1988). In Experiments 2 and 3, we employed these procedures to determine the effects of titles on the processing of ambiguous words. In Experiment 2 , instead of manipulating context in the immediately preceding sentence, context was manipulated by presenting or not presenting a title. In Experiment 3, all passages were presented with a title, but with either ambiguous words or length- and frequency-matched control words as target words.

In Experiment 2, the influence of titles on the processing of ambiguous words was examined by manipulating the presence of a title. If the title context acts the same way as a disambiguating local context, then both dominant and balanced meanings will be selectively accessed when preceded by a title, whereas subordinate meanings will not be. Thus, on the basis of previous findings consistent with the reordered access model, we would expect inflated reading times for the subordinate meanings even in the presence of a title, whereas the balanced meanings should be read faster with a title context.

\section{Method}

Participants. Twelve students at the University of Massachusetts participated in the experiment. The participants received either class credit or $\$ 8$ as compensation. All participants were native English speakers. They either had normal uncorrected vision or wore soft contact lenses.

Procedure and Apparatus. The procedure and apparatus were the same as in Experiment 1, except that no recall task was performed.

Materials. Four passages that could be interpreted from either of two perspectives were used. Two passages ("Baseball/Factory"; "Cards/Music") were adapted from Schallert (1976) and one ("Prisoner/Wrestler") was adapted from Anderson et al. (1977). The passages were formatted to fit 60 letters per line, no longer than 10 lines, and revised to include 5 ambiguous target nouns per passage. Target nouns appeared toward the middle of the line and never in the first or last lines of the passage. A fourth passage was created ("Lawyer/Vacation") similar to the others. The passages are included in Appendix B.

Twenty ambiguous nouns were included in the passages. When considered in the context of each title (e.g., the meaning instantiated by the title), 20 meanings were subordinate, 10 were dominant, and 10 were balanced meanings. Meaning frequencies for most of the ambiguous nouns were obtained from the Twilley, Dixon, Taylor, and Clark (1994) norms. Words not included in the Twilley et al. norms were classified according to a norming study using 50 students in the undergraduate subject pool at the University of Massachusetts at Amherst; the Twilley et al. and the local norms were consistent for all words that were included in both. The meaning 
Table 2

Reading Times, Regressions, and Measures of Individual Words in Experiment 2

\begin{tabular}{lcc}
\hline & \multicolumn{2}{c}{ Condition } \\
\cline { 2 - 3 } & Title & No Title \\
\hline Reading time per passage (sec) & 33.5 & 34.8 \\
Mean regression measures per passage & & \\
$\quad$ Time spent in regressions (msec) & 3,133 & 5,083 \\
$\quad$ Number of regressions made & 13.6 & 23.6 \\
Sentence wrap-up time (msec) & 303 & 378 \\
Individual noun measures (msec) & & \\
$\quad$ First fixation & 283 & 278 \\
$\quad$ Gaze duration & 304 & 327 \\
$\quad$ Total time & 348 & 398 \\
\hline
\end{tabular}

frequencies for the 20 subordinate meanings ranged from .00 to .30 ; the meaning frequencies for the 10 dominant meanings ranged from .61 to .98 ; the meaning frequencies for the 10 balanced meanings ranged from .31 to .60 . Because previous studies have traditionally used only very low frequency subordinate meanings, for the meaning analysis that was performed on the present data, the subordinate meanings that were required by the titles were broken down into two equal groups according to meaning frequency: frequent subordinate meanings ( 10 meanings generated between $30 \%$ and $7 \%$ of the time) and infrequent subordinate meanings ( 10 meanings generated less than $7 \%$ of the time). The infrequent subordinate category corresponds to the subordinate meanings that have been investigated in most previous research.

Words falling in the dominant meaning category had an average length of 5.6 letters and an average frequency of 65.2. Words in the balanced meaning category had an average length of 5.8 letters and an average frequency of 66.6 ; words in the frequent subordinate meaning category had an average length of 6.2 letters and an average frequency of 60.2 ; words in the infrequent subordinate meaning category had an average length of 5.2 letters and an average frequency of 84.6 .

Passages were presented in one of three conditions: without a title ("Get ready for the next passage"), with a strong title (the one the participants guessed most often when reading without a title), or with a weak title. All participants received one passage in each condition. The fourth passage repeated a condition and was counterbalanced for every 3 participants. The participants read two practice passages, followed by the test session that contained the four experimental passages and eight nonexperimental passages. Passages were presented in counterbalanced order. After each passage, the participants responded to a "yes" or "no" comprehension question.

\section{Results and Discussion}

Discourse-level measures. The first general question of interest was the replication of the discourse level reading measures from Experiment 1 and the integration measures in particular. Mean reading time for passages with strong titles was $32.6 \mathrm{sec}$, with weak titles was $34.5 \mathrm{sec}$, and with no title was $34.8 \mathrm{sec}$. In an overall ANOVA, the main effect for title neared significance $[F(2,22)=2.52$, $\left.M S_{\mathrm{e}}=6,863, p<.10\right]$. A post hoc comparison revealed that this was due to an advantage for passages with a strong title, since passages without titles tended to be read slower than passages with strong titles $[F(1,11)=3.8$, $\left.M S_{\mathrm{e}}=15,047, p<.08\right]$. Passages presented with weak titles were also read slower than passages with strong titles $\left[F(1,11)=6.06, M S_{\mathrm{e}}=7,427\right]$. Since the mean reading time was the only measure that yielded an effect of title strength, we have collapsed across strong and weak titles so that the comparison of interest in the remainder of the analyses is between title and no-title conditions.

The time that the participants spent in regressions is presented for title and no-title conditions in Table 2 . The participants spent less time in regressions when reading passages with titles than when reading untitled passages $\left[F(1,11)=27.1, M S_{\mathrm{e}}=841,664\right]$. Passages without titles also led to a greater number of regressions than did passages with titles $\left[F(1,11)=25.9, M S_{\mathrm{e}}=22.9\right]$.

End of sentence reading times (gaze durations on the last word in the sentence) were longer for untitled passages than for titled passages $\left[F_{1}(1,11)=14.9, M S_{\mathrm{e}}=\right.$ 2,$\left.264 ; F_{2}(1,46)=12.9, M S_{\mathrm{e}}=6,325\right]$. Mean wrap-up times for sentences are presented in Table 2 . Both the regression and the wrap-up results are consistent with the findings of Experiment 1 and further corroborate the influence of titles on discourse-level processing.

Word-level measures. The second major question of Experiment 2 was whether effects would be seen in the reading of individual ambiguous words. Mean gaze durations on ambiguous words are presented in Table 2; for completeness, first fixation and total time means are also presented. The target words were not fixated approximately $8 \%$ of the time. An additional $2 \%$ were eliminated due to fixations less than $140 \mathrm{msec}$ or greater than $800 \mathrm{msec}$. Gaze durations on ambiguous words were significantly shorter when preceded by a title than when preceded by no title $\left[F_{1}(1,11)=5.58, M S_{\mathrm{e}}=586 ; F_{2}(1,19)=\right.$ $\left.5.15, M S_{\mathrm{e}}=2,714\right]$

Because prior eye-movement studies of lexical ambiguity have demonstrated that context can speed the processing of balanced meanings but may not facilitate the processing of subordinate meanings of ambiguous words (Duffy et al., 1988; Rayner et al., 1994), gaze durations were analyzed in terms of meaning dominance (see Table 3). Gaze durations were analyzed by an ANOVA using four levels of frequency of intended meaning on the titled passages (dominant, balanced, frequent subordinate, infrequent subordinate) along with a fifth level for the untitled passages. A significant main effect was found due to the frequency of the intended meaning $\left[F_{1}(4,44)=\right.$ $\left.4.29, M S_{\mathrm{e}}=1,707\right]$. Tukey's HSD indicated that the presence of a title yielded shorter gaze durations on ambiguous words than in the untitled condition when a dominant $\left[F_{1}(1,11)=11.7, M S_{\mathrm{e}}=1,837 ; F 2(1,9)=3.72, M S_{\mathrm{e}}=\right.$ $3,455, p<.09]$, balanced $\left[F_{1}(1,11)=7.73, M S_{\mathrm{e}}=2,452\right.$; $\left.F_{2}(1,9)=15.6, M S_{\mathrm{e}}=18,542\right]$, or frequent subordinate $\left[F_{1}(1,11)=5.3, M S_{\mathrm{e}}=4,967 ; F_{2}(1,9)=4.48, M S_{\mathrm{e}}=\right.$ $6,944, p<.06]$ meaning of an ambiguous word was consistent with the title. When a title instantiated an infrequent subordinate meaning of an ambiguous word, gaze durations on the ambiguous word were not significantly shorter than in the untitled condition $\left(F_{\mathrm{S}}<1\right)$.

In summary, in Experiment 2, the presence of titles yielded similar effects on reading as in Experiment 1. Passages with titles tended to be read faster, with fewer 
Table 3

Gaze Durations (in Milliseconds) on Ambiguous Words by Meaning Frequency in Experiment 2

\begin{tabular}{lc}
\hline & Duration \\
\hline Title/Dominant & 285 \\
Title/Balanced & 288 \\
Title/Frequent subordinate & 280 \\
Title/Infrequent subordinate & 331 \\
No title/No intended meaning & 327 \\
\hline
\end{tabular}

regressions and shorter end-of-sentence reading times, than passages without titles. Also, gaze durations on individual words, for the most part, were shorter with titles. What determined whether a title yielded shorter gaze durations on the ambiguous words in these passages was the frequency of the meaning of the ambiguous word that was required by the title. All but the least frequent meanings resulted in shorter gaze durations with a title. Ambiguous words that needed to be resolved toward very infrequent subordinate meanings, on the other hand, resulted in gaze durations that were not different from those when there was no title. Thus, the title provided a strong context that influenced the access of dominant, balanced, and relatively frequent subordinate meanings of ambiguous words. But, the least frequent meanings were not processed more quickly as a function of the context instilled by the title. This result is consistent with prior studies (Binder \& Rayner, 1998; Rayner et al., 1994), which have traditionally used very low frequency subordinate meanings.

Control words matched for frequency are an important alternative baseline to titled (prior context) versus untitled (no context) presentation. Thus, in Experiment 3, we replicated the effect of titles on ambiguous words with length- and frequency-matched control words.

\section{EXPERIMENT 3 Effects of Title Context on Reading Lexically Ambiguous Words}

As already noted, previous eye-movement research on the resolution of lexical ambiguity has demonstrated that local context can decrease fixation times on ambiguous words when the context disambiguates a balanced meaning of the word (Duffy et al., 1988; Rayner \& Frazier, 1989; Rayner et al., 1994). However, the results of Experiment 2 suggest that the context instilled by a title can boost some subordinate meanings enough to be accessed before a dominant one. This is an important result, and in Experiment 3 we sought to replicate it by investigating whether titles allow for selective access of balanced and relatively frequent subordinate word meanings when compared to length and frequency matched control words.

\section{Method}

Participants. Twenty-four students at the University of Massachusetts participated in the experiment. The participants received either class credit or $\$ 8$ as compensation. All participants were native English speakers. They either had normal uncorrected vision or wore soft contact lenses.
}

Procedure and Apparatus. The procedure and apparatus were the same as in Experiment 2

Materials. The four passages from Experiment 2 were used with slight changes to two of the passages. One sentence was added to the "Baseball/Factory" and "Prison/Wrestling" passages (included in italics in the Appendix B version of the passages). The word plate was used instead of $f l y$, and the word $c l u b$ was used instead of guard. These changes were made due to difficulty coming up with control words and a concern that the same meaning of each word might be taken with either title.

As in Experiment 2, 20 ambiguous nouns were included in the passages. The meanings that were required by the titles were broken down into four groups: dominant meanings ( 10 meanings generated $70 \%$ of the time or more), balanced meanings ( 10 meanings generated between .62 and .32), frequent subordinate meanings ( 10 meanings generated between .08 and .30 ), and infrequent subordinate meanings (generated less than $8 \%$ of the time) according to Twilley et al. (1994) and local norms. The dominant and infrequent subordinate categories correspond to the dominant and subordinate meanings that have been investigated in most previous research.

All passages were presented with a title, but, on half of the passages, the ambiguous words were replaced with control words, matched as closely as possible for meaningfulness, length, and frequency using Francis and Kučera's (1982) norms. The control words are presented in parentheses following each ambiguous word in Appendix B. The average word frequency was 70.15 for the ambiguous words and 63.05 for the control words. Because the fit of the control words into passages was important, in a few cases, the control word was a letter longer or (usually) shorter than the ambiguous word. The average length of ambiguous words was 5.75 letters, and the average length of the control words was 5.5 letters. The intention was that if the length of the control words could not be matched exactly, then the control word should be shorter, so that any effect found on the reading times of ambiguous words would not be due to inflated reading times on control words due to length. Each participant read two passages with ambiguous words and two passages with control words.

The participants read two practice passages, followed by the four experimental passages intermixed with eight nonexperimental passages. Passages were presented in counterbalanced order. After each passage, the participants responded to a "yes" or "no" comprehension question.

\section{Results and Discussion}

Reading times were measured on the ambiguous and matched control words. There was a failure to fixate on approximately $6 \%$ of the target words, but there were no differences across conditions. An additional $3.75 \%$ of the data were eliminated due to fixations shorter than $140 \mathrm{msec}$ or longer than $800 \mathrm{msec}$.

The main interest of Experiment 3 was whether we would replicate the effects of titles seen in Experiment 2 as a function of the relative frequency of the intended meanings of ambiguous words. Table 4 shows the mean first fixation, gaze duration, and total reading times for the critical words in each condition. On the basis of the results of Experiment 2, planned comparisons were carried out between the ambiguous and control words at each level of meaning frequency. These comparisons revealed that gaze durations were significantly longer on ambiguous words than on control words when the title was consistent with infrequent meanings $\left[F_{1}(1,23)=4.41, M S_{\mathrm{e}}=\right.$ 14,$\left.253 ; F_{2}(1,9)=11.6, M S_{\mathrm{e}}=1,507\right]$. The participants did not take longer on ambiguous words than on control 
Table 4

Reading Time Measures (in Milliseconds) on Ambiguous and Control Words In Experiment 3

\begin{tabular}{lll}
\hline & \multicolumn{2}{c}{ Words } \\
\cline { 2 - 3 } & Ambiguous & Control \\
\hline First fixation & 276 & 278 \\
Dominant & 284 & 285 \\
Balanced & 291 & 293 \\
Frequent subordinate & 302 & 282 \\
Infrequent subordinate & & \\
Gaze duration & 316 & 337 \\
Dominant & 337 & 336 \\
Balanced & 299 & 304 \\
Frequent subordinate & 357 & 305 \\
Infrequent subordinate & & \\
Total time & 373 & 394 \\
Dominant & 368 & 371 \\
Balanced & 353 & 338 \\
Frequent subordinate & 398 & 348 \\
Infrequent subordinate & & \\
\hline
\end{tabular}

words when the title instantiated a frequent subordinate meaning, a balanced meaning, or a dominant meaning of an ambiguous word (all $F \mathrm{~s}<1$ ). This pattern of results is thus consistent with the findings from Experiment 2 that titles can allow for the selective access of all but the least frequent meanings of ambiguous words.

\section{GENERAL DISCUSSION}

In the present experiments, we replicated the classic effect of titles on memory-namely, titles were found to improve the recall of text. We also found that the participants showed a reading-time advantage for passages with a title. Although titles have generally been thought to facilitate comprehension at integrative stages of processing, advantages were found both at the discourse level (the participants made fewer regressions and spent less time at the end of sentences when they had a title) and at an individual word level (the participants' gaze durations were shorter on nouns when they had a title than when they did not). These results extend previous investigations of title effects by showing that titles can facilitate processing at multiple levels. At one level, the presence of a title can facilitate the integration of propositions or discourse entities. When textual information has been adequately incorporated into a mental representation, fewer regressions are necessary and less time is spent in sentence wrap-up, thus speeding reading. In addition, the results suggest facilitation may also be found at a lexical level, since nouns were read faster when passages were presented with titles. Furthermore, except when a very infrequent sense of an ambiguous noun was required, titles allowed for selective access of the intended meanings of ambiguous nouns. Thus, these results extend our previous knowledge of title effects by showing that titles can facilitate processing even at a lexical level.

In addition, these results have implications for models of lexical access, as well as more general models of text or discourse comprehension. In relation to lexical access, a major issue has been when the effect of context can be seen in the course of meaning resolution. Specifically, the issue revolves around how early context effects may be seen. One extreme on this issue is that context plays no role in initial access and that the first stage of processing is autonomous and independent, occurring wholly on the basis of relative frequency that can be computed within the lexicon (Fodor, 1983; Forster, 1979). The opposite extreme is that lexical access is wholly interactive or context dependent and that a strong context can determine meaning selection at the earliest stages of processing (Marslen-Wilson \& Tyler, 1987; McClelland, 1987). The presence of the subordinate bias effect in previous studies, as well as in the present experiments, suggests that meaning selection is not the result of a purely interactive or context-dependent process. That is, an appropriate context does not always allow quick access to just the context appropriate meaning. On the other hand, the present data do not support a wholly autonomous view either. Specifically, the lack of a subordinate bias effect on the more frequent subordinate meanings suggests that context may play a greater role in meaning access than previously suggested by eye-movement studies and can interact with meaning frequency and allow for quick access of the appropriate meaning as long as the meaning is relatively frequent.

There are a number of possible reasons why the present experiments may have shown more extensive effects of context on lexical access than have been observed previously. The first reason may be the nature of the materials. These passages may seem quite difficult, abstract, or vague, especially when presented without titles, which may have produced a difficult reading situation. Rayner and Pollatsek (1989) have suggested that context may have a larger effect on lexical access in situations in which basic reading processes are slowed. Thus, the larger effects of context demonstrated here may in part be a reflection of the strangeness of these passages.

A second possible reason for the greater effects of context demonstrated here is because these experiments included more frequent subordinate meanings than have usually been examined. Traditionally, the subordinate meanings that have been studied usually have frequencies of $10 \%$ or less. Hence, the present data should be taken as a complement to previous studies. This is an important result because it demonstrates with eye-movement data that context can boost a subordinate meaning to a level above a dominant but nonintended meaning and eliminate the subordinate bias effect. However, in these experiments, the most infrequent meanings remained least accessible regardless of the strong global context provided by the title. This suggests that meaning frequency does have the last word in lexical access.

Taken as a whole, the results of Experiments 2 and 3 are consistent with the reordered access model in which context can boost the activation of meanings based on their frequency. However, the results are also consistent with a context-sensitive approach, in which context guides but does not necessarily determine meaning access (Paul, 
Kellas, Martin, \& Clark, 1992). Both of these approaches can account for the present results if we assume that meaning frequency acts as a default for activation level, and context effects are a function of the basic activation due to frequency. The default role of meaning frequency preserves an independent role for the lexicon. However, the fast reading times on the more frequent subordinate meanings of ambiguous words suggest that context can allow for the selective access of some subordinate senses.

In relation to more general models of text or discourse comprehension, Hess, Foss, and Carroll (1995) have suggested that facilitation associated with global discourse context can be due to either the ease of identifying new discourse entities or the ease of integrating new entities into the ongoing discourse representation. The results of the present experiments confirm that titles effect processing at both levels.

\section{REFERENCES}

Anderson, R. C., Reynolds, R. E., Schallert, D. L., \& Goetz, E. T. (1977). Frameworks for comprehending discourse. American Educational Research Journal, 14, 367-381.

Balota, D. A., Pollatsek, A., \& Rayner, K. (1985). The interaction of contextual constraints and parafoveal visual information in reading. Cognitive Psychology, 17, 364-390.

Binder, K. S., \& Rayner, K. (1998). Contextual strength does not modulate the subordinate bias effect: Evidence from eye fixations and self-paced reading. Psychonomic Bulletin \& Review, 5, 271-276.

Blanchard, H. E., \& Iran-Nejad, A. (1987). Comprehension processes and eye movement patterns in the reading of surprise-ending stories. Discourse Processes, 10, 127-138.

Bransford, J. D., \& Johnson, M. K. (1972). Contextual prerequisites for understanding: Some investigations of comprehension and recall. Journal of Verbal Learning \& Verbal Behavior, 11, 717-726.

DoOLING, D. J., \& LACHMAN, R. (1971). Effects of comprehension on retention of prose. Journal of Experimental Psvchologv, 88, 216-222.

DOPKINS, S., MorRis, R. K., \& RAYNER, K. (1992). Lexical ambiguity and eye fixations in reading: A test of competing models of lexical ambiguity resolution. Journal of Memory \& Language, 31, 461-476.

DUFFY, S. A., MORRIS, R. K., \& RAYNER, K. (1988). Lexical ambiguity and fixation times in reading. Journal of Memory \& Language, 27, 429-446.

EhrLich, K., \& RAYNER, K. (1983). Pronoun assignment and semantic integration during reading: Eye movements and immediacy of processing. Journal of Verbal Learning \& Verbal Behavior, 22, 75-87.

FODOR, J. (1983). Modularity of mind. Cambridge, MA: MIT Press.

FORSTER, K. I. (1979). Levels of processing and the structure of the language processor. In W. E. Cooper \& E. C. T. Walker (Eds.), Sentence processing: Psvcholinguistic studies presented to Merrill Garrett (pp. 27-85). Hillsdale, NJ: Erlbaum.

FRANCIS, W., \& KUČERA, H. (1982). Word-frequency counts of modern English. Providence, RI: Brown University Press.

FRAZIER, L.. \& RAYNER, K. (1982). Making and correcting errors during sentence comprehension: Eye movements in the analysis of structurally ambiguous sentences. Cognitive Psychologv, 14, 178-210.

Hess, D. J., Foss, D. J.. \& CarroLl, P. (1995). Effects of global and local context on lexical processing during language comprehension. Journal of Experimental Psychology: General, 124, 62-82.

HYöNÖ. J. (1993). Effects of thematic and lexical priming on readers eye movements. Scandinavian Journal of Psychology, 34, 293-304.

INHOFF, A. W. (1984). Two stages of word processing during eye fixations in the reading of prose. Journal of Verbal Learning \& Verbal Behavior, 23, 612-624.

Just, M. A., \& CARPENTER, P. A. (1978). Inference processing during reading: Reflections from eye fixations. In J. W. Senders, D. F. Fisher, \& R. A. Monty (Eds.), Eye movements and the higher psychological functions (pp. 157-174). Hillsdale, NJ: Erlbaum.
Just, M. A., \& Carpenter, P. A. (1980). A theory of reading: From eye fixations to comprehension. Psychological Review, 87, 329-354.

KINTSCH, W. (1988). The role of knowledge in discourse comprehension: A construction-integration model. Psychological Review, 95 163-182.

MarSLEN-Wilson, W., \& TYler, L. K. (1987). Against modularity. In J. Garfield (Ed.), Modularity in knowledge representation and natural language understanding (pp. 37-62). Cambridge, MA: MIT Press.

MCCLELLAND, J. L. (1987) The case for interactionism in language processing. In M. Coltheart (Ed.), Attention and performance XII: The psychology of reading (pp. 3-36). Hillsdale, NJ: Erlbaum.

MoRRIS, R. K. (1994). Lexical and message-level sentence contexts effects on fixation times in reading. Journal of Experimental Psychology: Learning, Memory, \& Cognition, 20, 92-103.

MORRISON, R. (1984). Manipulation of stimulus onset delay in reading: Evidence for parallel programming of saccades. Journal of Experimental Psychology: Human Perception \& Performance, 10, 667-682.

Paul, S. T., Kellas, G., Martin, M., \& Clark, M. B. (1992). The influence of contextual features on the activation of ambiguous word meanings. Journal of Experimental Psychology: Learning, Memory, \& Cognition, 18, 703-717.

RAYNER, K. (1998). Eye movements in reading and information processing: 20 years of research. Psychological Bulletin, 124, 372-422.

Rayner, K., Binder, K. S., \& Duffy, S. A. (1999). Contextual strength and the subordinate bias effect. Quarterly Journal of Experimental Psychology, 52A, 841-852.

RAYNER, K. \& DUFFY, S. A. (1986). Lexical complexity and fixation times in reading: Effects of word frequency, verb complexity, and lexical ambiguity. Memory \& Cognition, 14, 191-201.

Rayner, K., \& Frazier, L. (1989). Selection mechanisms in reading lexically ambiguous words. Journal of Experimental Psychology: Learning, Memory, \& Cognition, 15, 779-790.

Rayner, K., Kambe, G. A., \& Duffy, S. A. (2000). The effect of clause wrap-up on eye movements in reading. Quarterly Journal of Experimental Psychology, 53A, 1061-1080.

RaYner, K., Pacht, J. M., \& DufFy, S. A. (1994). Effects of prior encounter and global discourse bias on the processing of lexically ambiguous words: Evidence from eye fixations. Journal of Memory \& Language, 33, 527-544.

RAYNER, K., \& POllatSEK, A. (1989). The psychology of reading. Englewood Cliffs, NJ: Prentice Hall.

Rayner, K., Sereno, S. C., Morris, R. K., Schmauder, A. R., \& Clifton, C. (1989). Eye movements and on-line language comprehension processes. Language \& Cognitive Processes, 4, 2 l-49.

RAYNER, K., \& WELL., A. D. (1996). Effects of contextual constraint on eye movements in reading: A further examination. Psychonomic Bulletin \& Review, 3, 504-509.

Reichle, E. D., Pollatsek. A., Fisher, D. L., \& Rayner, K. (1998), Toward a model of eye movement control in reading. Psychological Review, 105, 125-157.

SCHALLERT, D. (1976). Improving memory for prose: The relationship between depth of processing and context. Journal of Verbal Learning \& Verbal Behavior, 15, 621-632.

SChilling, H. E. H., Rayner, K., \& Chumbley, J. I. (1998). Comparing naming, lexical decision, and eye fixation times: Word frequency effects and individual differences. Memory \& Cognition, 26, 1270-1281.

Schustack, M. W., Ehrlich, S. F., \& Rayner, K. (1987). The complexity of contextual information in reading: Local and global influences. Journal of Memory \& Language, 26, 322-340.

Sereno, S., PACHT, J. M., \& RaYNer, K. (1992). The effect of meaning frequency on processing lexically ambiguous words: Evidence from eye fixations. Psychological Science, 3, 296-300.

Shebilske, W. L., \& Fisher, D. F. (1983). Eye movements and context effects during reading of extended discourse. In K. Rayner (Ed.), Eye movements in reading: Perceptual and language processes ( $\mathrm{pp} .153-$ 179). New York: Academic Press.

Smith, E. E., \& Swinney, D. A. (1992). The role of schemas in reading text: A real-time examination. Discourse Processes, 15, 303-316.

St. George, M., Mannes. S., \& Hoffman, J. E. (1994). Global semantic expectancy and language comprehension. Journal of Cognitive Neuroscience, 6, 70-83. 
ThoRndyke, P. W. (1977). Cognitive structures in comprehension memory of narrative discourse. Cognitive Psychology, 9, 77-110.

Twilley, L. C., Dixon, P., Taylor, D., \& Clark, K. (1994). University of Alberta norms of relative meaning frequency for 566 homographs. Memory \& Cognition, 22, 111-126.

VAuras, M., HYöNö, J., \& Niemi, P. (1992). Comprehension coherent and incoherent texts: Evidence from eye movement patterns and recall performance. Journal of Research in Reading, 15, 39-54.

Vu, H., \& Kellas, G. (1999). Contextual strength modulates the subordinate bias effect: Reply to Rayner et al. Quarterly Journal of Experimental Psychology, 52A, 853-855.

\section{NOTES}

1. While it is the case that fixation times on words can be influenced by postaccess integration or higher order processes, most of the variability in fixation times is due to the ease or difficulty of lexical processing (see Rayner, 1998). Furthermore, Schilling, Rayner, and Chum- bley (1998) demonstrated that fixation times on words and naming times (which are generally assumed to be reflective of lexical access processes) are highly correlated. The model of eye-movement control in reading (the E-Z Reader model) described by Reichle, Pollatsek, Fisher, and Rayner (1998) assumes that lexical processes are the trigger moving the eyes through text (and justification for that assumption is provided by Reichle et al.), and we will adopt that same assumption here.

2. Although the subordinate bias effect has been used as the battleground to discriminate between alternate models of lexical ambiguity resolution, Rayner, Binder, and Duffy (1999) have pointed out that, in principle, the reordered access model can account for contextual override of the effect.

3. Inhoff (1984) initially argued that first-fixation duration reflects lexical access processes and that gaze duration reflects lexical access and integration processes. However, subsequent research has suggested that the distinction does not hold and that both measures often yield similar results. Most studies now typically focus on the gaze duration as a measure of lexical processing (see Rayner, 1998).

\section{APPENDIX A \\ Experiment 1 Passages}

(Bold items are words included in individual words analysis. Underlined phrases are items included in empty phrase analysis.)

Making and Flying a Kite

A newspaper is better than a magazine. A seashore is a better place than the street. At first it is better to run than to walk. You may have to try several times. It takes some skill but it's easy to learn. Even young children can enjoy it. Once successful, complications are minimal. Birds seldom get too close. Rain, however, soaks in very fast. Too many people doing the same thing can also cause problems. One needs lots of room. If there are no complications, it can be very peaceful. A rock will serve as an anchor. If things break loose from it, however, you will not get a second chance.

Do you need a lot of room?

Discovering America

With hocked gems financing him, our hero bravely defied all scornful laughter that tried to prevent his scheme. Your eyes deceive, he had said. An egg, not a table, correctly typifies this unexplored planet. Now three sturdy sisters sought proof, forging along sometimes through calm vastness, yet more often over turbulent peaks and valleys. Days became weeks as many doubters spread fearful rumors about the edge. At last, from nowhere, welcome winged creatures appeared signifying momentous success.

Were there four sisters?

Space Trip to the Moon

Joe looked outside from cramped quarters. Numerous unknown objects moved swiftly by in vague blackness around his field. Two fearless companions worked along manipulating buttons while reading complex patterns. Flat familiar homeland now resembled a tiny rubber ball. Everyone here and at home knew that only lifeless things would be found among huge cold mountains surrounding deep barren valleys. But all important papers anxiously awaited their arrival for no man had ever made such big news.

Were there two companions?

Washing Clothes

The procedure is actually quite simple. First you arrange things into different groups depending on their makeup. Of course, one pile may be sufficient depending on how much there is. If you have to go somewhere else due to lack of facilities that is the next step. It is important not to overdo it. It is better to do too few things at once than too many. This may seem unimportant, but complications from doing too many can easily arise. A mistake can be expensive. The manipulation of the appropriate mechanisms should be obvious. At first the whole procedure may seem complicated, but soon it will become just another facet of life. It is hard to foresee any end to the need for this task.

Is it easy to foresee an end to the need for this task? 


\section{APPENDIX B \\ Experiment 2 and 3 Passages}

(Bold items are words included in ambiguous words analysis. Italics represent sentences included for Experiment 3 only. In parentheses are the control words for items used in Experiment 3 and relative frequency for each sense of each ambiguous word, with respect to the listed titles.)

Worries of a Baseball Team Manager/Worries of a Ceramics Factory Manager

In the last days of August, we were all suffering from the unbearable heat. Our daily job had turned from fun into hard labor. "All we need now is a strike (injury .30/profit .25)," said the manager. The tone of his voice warned that he was about to leave the field (park .98/office .00). I could not help him. I hit a fly (.00/.34). "I guess things could get even worse," he sighed. "Our most valuable pitchers (players .48/pottery .49) could crack in this heat. If only we had a lot more fans (wins .62/rain .24), we would all feel better." I stared silently at the plate (fence $.04 /$ dish .72) in front of me. "Or, if our best man came home I'd be happier," he continued. "Oh well, a walk would cheer me up a little," the manager said as he turned away.

Did this take place in July?

A Group of Friends Plays Gin Rummy/Rehearsal Section of a Musical Ensemble

Every Saturday, four friends get together. When Jerry, Mike and Pat arrived, Karen was in her living room writing some notes (bills .84/songs . 10). She quickly stood up, gathered the cards, and greeted her friends. As usual they couldn't decide what to play. Jerry finally took a stand (drink $.89 /$ chair .04 ) and set things up. As they began, Karen's recorder (stereo .70 /keyboard .08 ) filled the room with soft music. Mike noticed Pat's hand and the large number of diamonds (queens .04/emeralds .89) early in the evening. As the night progressed, the tempo of play increased. At a lull, Jerry pondered the arrangement in front of him. Mike wanted to hear the score (rules .72/start .04). They listened and commented on their performance. After the comments, Karen's friends went home.

Do they play on Fridays?

A Deposed Leader Trying to Escape from Prison/A Wrestler Trying to Escape his Opponent Jim slowly got up from the mat, planning his escape. He sat a bit and thought. Things were not going well. What bothered him most was being held, especially since the charge (claims $.07 /$ attack .10) against him had been weak. He considered the present situation. The lock (jail $.96 /$ grip .00 ) that held him was strong but he could break out of it. He really needed a pin (ally $.46 /$ move.04). He had to be careful. His guard $(.60 / .04)$ was up. A successful escape would depend on the next few seconds. He had a strong club (army .23/team .45) behind him which might help in the end. Since the last fall (June .36/loss .55) he had become desperate. He was tired of the pressure. Jim was ready for action.

Did Jim mind being held?

A Lawyer Packs up after Court/A Woman Packs for her Honeymoon

Susan sat and thought for a while. She liked to mull over decisions. She didn't know which of the two suits (firms .02/coats .83 ) to pick. She had to choose and they both had an appeal. She got up and started gathering her things. She thought about the additional charges (claims .10 /purchases .48 ) made today as she picked up some new articles (reports .58/clothes .24). She feared her final statement (argument .32/payment .02). She would have to be careful not to overdo it. The huge case was going to be hard enough to close already. Because she was the last in the room, she checked to make sure nothing was left. She found some briefs (memos .10/ slacks .76) on a chair that were forgotten by her partner. She stuffed them into the pocket of her bag, and with a final satisfied glance walked out the door.

Was Susan the last one in the room?

(Manuscript received June 8, 1998;

revision accepted for publication September 3, 1999.) 